\title{
PROBLEMÁTICA DA INVESTIGAÇÃO EDUCATIVA A PARTIR DA LÓGICA DA EPISTEMOLOGIA E DA PRODUÇÃO CIENTÍFICA
}

\section{SÁNCHEZ GAMBOA, S. Fundamentos para la investigación educativa:} presupuestos epistemológicos que orientam al investigador. Santa Fé de Bogotá: Cooperativa Editorial Magistério, 1998.

\section{Carolina Messora Bagnolo}

O livro escrito pelo autor Silvio Sánchez Gamboa que recomendamos para leitura tanto aos iniciantes quanto para os mais experientes na pesquisa, é a publicação $n^{\circ} 66$ com 144p. da Cooperativa Editorial Magistério que congrega na forma de coleção Mesas Redondas, constituídas de obras com autores conhecidos e especializadas em diferentes áreas da pedagogia e da educação. Sua primeira edição foi lançada em 1998 com 2.000 exemplares e uma re-impressão no ano de 2001, com 1.000 exemplares. Como se trata de um tema de leitura importante para os pesquisadores nos diferentes estágios das diferentes áreas do conhecimento (educação, educação física, matemática, química, comunicação) e, sendo escrito em espanhol, sugerimos uma nova edição na língua portuguesa.

Inicia com uma apresentação de Guillermo Hoyos Vázquez do Departamento de Filosofia da Universidade Nacional da Colômbia em junho de 1998, seguidos de uma introdução e sete capítulos que reúnem uma série de artigos publicados em várias revistas brasileiras e colombianas, assim como conferências apresentadas em congressos internacionais da Argentina, Brasil, Colômbia, Chile, Cuba, México e Venezuela, que tem em comum o estudo da problemática da investigação educativa a partir da lógica da epistemologia e da produção científica.

O autor faz uma crítica sobre as publicações sobre o tema que se centraliza geralmente em questões técnicas e metodológicas, em sua maioria na visão positivista, considerada uma tendência predominante na investigação educativa, e que somente admite um único método científico, seguindo o estatuto da ciência positivista, o processo empíricoanalítico e as regras do discurso hipotético-dedutivo. Grandes partes dos textos publicados são destacadas em três grupos: 1 . Numerosos manuais que explicam as técnicas da investigação, procedimentos, formas de elaboração dos instrumentos, esquemas de investigação e modelos 
de apresentação de trabalhos científicos, que desconhecem uma análise da produção científica e dos requisitos básicos da lógica e da epistemologia; 2. A dificuldade de estudantes e profissionais às obras de elevado nível teórico-filosófico; 3. Resultados de trabalhos que indicam superficialmente alguns procedimentos e referências sem realizar uma reflexão sobre os processos e sobre a construção do conhecimento.

Para que o leitor assimile novos métodos, novas tendências epistemológicas e a relação lógica entre métodos e epistemologia na investigação educativa, o autor chama a atenção que será necessário aceitar fundamentalmente duas teses: a primeira de admitir a pluralidade de abordagens e a diversidade de maneiras de ver e enfocar a problemática educativa; e a segunda, admitir a necessária relação lógica entre os processos instrumentais (técnicas e metodologias) de investigação, os referenciais teóricos e as concepções epistemológicas. Ao discutir sobre métodos e epistemologias pretende recuperar os nexos entre a prática da investigação, expressada nos métodos e na reflexão sobre suas articulações lógicas com os pressupostos epistemológicos.

O livro está organizado em duas grandes partes: os três primeiros capítulos oferecem algumas concepções básicas da investigação educativa, métodos e epistemologias e definem as bases do instrumental utilizado na análise da sua produção. Os capítulos restantes pontuam os resultados de alguns estudos sobre as investigações educativas em alguns cursos de pós-graduação na área; enfocam tendências epistemológicas que orientam essas investigações; recuperam suas implicações em relação com as categorias filosóficas de homem, relação sujeito-objeto, história e realidade e discutem os problemas éticos próprios da produção do conhecimento sobre a sociedade e a educação.

O primeiro capítulo “Alternativas metodológicas: uma análise epistemológica” contém um resumo da dissertação de mestrado “Análise epistemológica dos métodos na pesquisa educacional”, apresentada na Universidade de Brasília em 1982. O segundo capítulo “Esquema paradigmático: um instrumento para a análise da produção científica”, trata do instrumental utilizado na análise da pós-graduação científica e que ajuda a identificar as partes constitutivas da investigação em educação e reconstituir a lógica interna que toda investigação deve conter. O terceiro capítulo “A formação do investigador em educação”, apresenta alguns resultados da tese de doutorado em Filosofia e História da Educação, "Epistemologia em Educação”, defendida na Faculdade de Educação da Unicamp em 1987. 
Os capítulos seguintes são dedicados à exposição e reflexão sobre alguns resultados de análises da prática da investigação e suas relações com as teorias do conhecimento e com as visões de mundo que sustentam.

O quarto capítulo discute “A construção do objeto na investigação em educação: enfoques epistemológicos”, que alerta a necessidade do investigador revelar as teorias do conhecimento que dão fundamento aos métodos e as epistemologias em toda investigação científica. O quinto capítulo “A concepção de homem: algumas verificações” refletem sobre a articulação existente entre as abordagens teórico-metodológicas utilizadas na investigação educativa e seus pressupostos filosóficos. O sexto capítulo “A historicidade do objeto”, defende a tese de que dependendo do método utilizado, se ignora, se menospreza ou se ressalta o atributo essencial dos fenômenos sociais, além de questionar as limitações de alguns dos modelos teóricos para expressar a historicidade. O sétimo capítulo "Interesses cognitivos: uma questão ética?”, discute a problemática ética da investigação científica, e, pergunta se existe uma dimensão ética na opção do investigador por determinada abordagem teóricometodológica. Considera que o investigador deve ter consciência clara dos interesses que comandam sua investigação.

Essas articulações são consideradas necessárias pelo autor para garantir o rigor lógico e a qualidade da produção científica na área da educação, porém, hoje em dia, após sete anos da primeira publicação constatamos que todos os pesquisadores das diferentes áreas devem observar o fio condutor que articula as partes na unidade temática de suas investigações em busca de articulações lógicas entre métodos e epistemologias. 
